\title{
The Effect of Cardiac Filling on Heart Rate Variability in Rabbit Isolated Heart
}

\author{
Oto Janousek ${ }^{1}$, Marina Ronzhina ${ }^{1}$, Jakub Hejc ${ }^{1}$, Tibor Stracina ${ }^{2}$, Veronika Olejnickova ${ }^{2}$, \\ Marie Novakova ${ }^{2}$, Ivo Provaznik ${ }^{1}$, Jana Kolarova ${ }^{1}$ \\ ${ }^{1}$ Department of Biomedical Engineering, Brno University of Technology, Brno, Czech Republic \\ ${ }^{2}$ Department of Physiology, Faculty of Medicine, Masaryk University, Brno, Czech Republic
}

\begin{abstract}
Presence of heart rate variability (HRV) in isolated hearts is widely recognized; however, its mechanisms are still subject of debate. One of the possible explanations is that mechanoreceptors in cardiac tissue affect HRV. In order to evaluate possible dependence of HRV on heart mechanoreceptors activated during left ventricle filling, the HRV parameters in two perfusion modes of isolated heart were compared: Langendorff and working heart mode. Ten New Zealand rabbit isolated hearts were perfused (Krebs-Henseleit, $37^{\circ} \mathrm{C}, \quad 85 \mathrm{mmHg}$ ) in Langendorff mode and consecutively in working heart mode ( $8 \mathrm{cmH}_{2} \mathrm{O}$ preload, $60 \mathrm{cmH}_{2} \mathrm{O}$ afterload). A total of $27 \mathrm{HRV}$ parameters in time, frequency, geometric, and non-linear domain were computed. No significant differences (Wilcoxon signed rank test, $p<0.05$ ) were found among all studied HRV parameters between Langendorff and working heart mode. The study confirms the presence of heart rate fluctuation in isolated hearts in both Langendorff and working heart modes. Results of statistical analysis show that heart rate fluctuation is irrespective to mechanical stimulation of heart during atrium and ventricle filling.
\end{abstract}

\section{Introduction}

Presence of heart rate variability (HRV) in isolated hearts is widely recognized; however, its mechanisms are still subject of debate. One of the possible explanations is that mechanoreceptors in cardiac tissue affect HRV. This hypothesis is supported by the fact that mechanical stimulus can induce changes of heart rhythm [1, 2]. In order to evaluate effect of mechanical stimulation of isolated heart during atrium and ventricle filling, HRV parameters were compared between Langendorff and working heart modes.

\section{Method}

Ten New Zealand rabbit isolated hearts (both sex) were studied. All experiments followed the guidelines for animal treatment approved by local authorities and conformed to the EU law.

\subsection{Isolated hearts}

In deep anaesthesia with xylasin and ketamine, the hearts were excised and perfused in Langendorff mode (constant pressure of $85 \mathrm{mmHg}$ ) and consecutively in working heart mode $\left(8 \mathrm{cmH}_{2} \mathrm{O}\right.$ preload, $60 \mathrm{cmH}_{2} \mathrm{O}$ afterload) with Krebs-Henseleit solution (in $\mathrm{mM}: \mathrm{NaCl}$ 118, $\mathrm{NaHCO}_{3} 24, \mathrm{KCl} 4.2, \mathrm{KH}_{2} \mathrm{PO}_{4}$ 1.2, $\mathrm{MgCl}_{2}$ 1.2, glucose 5.5, Taurine 10, and $\mathrm{CaCl}_{2}$ 1.2). The KrebsHenseleit solution was continuously oxygenated with $95 \%$ $\mathrm{O}_{2}$ and $5 \% \mathrm{CO}_{2}$ and solution temperature was stabilized at $37^{\circ} \mathrm{C}$ in order to avoid temperature effect on RR intervals. The isolated heart itself was submerged in Krebs-Henseleit solution in bath tempered $\left(37^{\circ} \mathrm{C}\right)$ with water jacketed system. The details of perfusion system have been published previously [3]. Stabilization of temperature was secured by closed-loop of temperature sensor and feedback controlled thermostat, resulting in precision under $0.1^{\circ} \mathrm{C}$.

\subsection{Data acquisition}

Electrograms of 5 minutes duration were recorded in Langendorff and working heart modes. The 30 minutes long stabilization period preceded recording in Langendorff mode to avoid effect of heart excision and cannulation.

Electrograms were recorded by touch-less method [4] with sampling frequency of $10 \mathrm{kHz}$ and with 12-bit resolution (PCI-6111E, National Instruments) by custom software (LabView 2010). Electrograms degraded by noise were excluded from further processing.

R-peaks were automatically detected by own R-wave detector (Matlab R2013a, MathWorks) and carefully reviewed by human. Tachograms were then obtained from RR series.

\section{3. $\quad$ Preprocessing}


Preprocessing of RR interval was applied on recorded data with aim to reduce analysis errors. The three preprocessing steps were performed on RR series: detrending, resampling and ectopic beat correction. Detrending using wavelet transform alleviated any nonstationarities within RR series using smoothness prior approach. Resampling at $10 \mathrm{~Hz}$ ensured equidistant sampling of RR series requiring for correct calculation of frequency domain parameters. Ectopic beat correction process removed any kind of false R-peak detection or cardiac ectopy, which were longer than $20 \%$ of RR mean or quadruple of RR standard deviation.

\subsection{HRV parameter evaluation}

A total of $27 \mathrm{HRV}$ parameters in time, frequency, geometric, and non-linear domain were computed from RR series. In order to facilitate comparison of results, the parameters recommended by Task Force [5] were computed. Time domain parameters include $R R$ mean, $R R$ median, SDNN, NN50, pNN50, and RMSSD. Geometric domain parameters include triangular index $H R V T i$ and triangular interpolation of histogram TINN. Frequency domain parameters include total amount of power aTotal and powers in standardized frequency bands $a V L F, a L F$, $a H F$ with their normalized correlates $n L F, n H F$ and its ratio $L F / H F$. Peak frequencies in each band were computed as $p V L F, p L F$ and $p H F$. The frequency band were defined according to the table 1 .

Table 1. HRV frequency bands.

\begin{tabular}{ll}
\hline Band name, abbreviation & Frequency range [Hz] \\
\hline Very low freq. (VLF) & $0-0.04$ \\
Low frequency (LF) & $0.04-0.15$ \\
High frequency (HF) & $0.15-0.4$ \\
\hline
\end{tabular}

Estimating of power spectrum density were performed using both non-parametric fast Fourier transform and parametric autoregressive modelling. Autoregressive modelling were performed using Burg model with the $16^{\text {th }}$ order. Since there was no significant difference between parameters computed by these two methods, only result from autoregressive modelling are shown in Table 3. Nonlinear parameters include Poincaré diagram identifiers SD1 and SD2, sample entropy SampEn and scaling exponents of detrended fluctuation analysis alpha, alpha1 and alpha2 with breakpoint scale equal to 10 .

Analysed HRV parameters are summarized in table 2. All HRV parameters were estimated by HRVAS software [6] using Matlab (Matlab R2009, MathWorks).
Table 2. HRV parameters with short description.

\begin{tabular}{|c|c|}
\hline $\begin{array}{l}\text { HRV } \\
\text { parameter }\end{array}$ & Short description of HRV parameter \\
\hline RR mean & mean of RR interval \\
\hline RR median & median of RR interval \\
\hline SDNN & standard deviation of RR intervals \\
\hline NN10 & $\begin{array}{l}\text { number of successive differences that } \\
\text { are greater than } 10 \text { milliseconds }\end{array}$ \\
\hline pNN10 & $\begin{array}{l}\text { percentage of successive differences } \\
\text { that are greater than } 10 \text { milliseconds }\end{array}$ \\
\hline RMSSD & $\begin{array}{l}\text { root mean square of successive } \\
\text { differences of RR intervals }\end{array}$ \\
\hline HRVTi & triangular index \\
\hline TINN & $\begin{array}{l}\text { triangular interpolation of the RR } \\
\text { interval histogram }\end{array}$ \\
\hline $\mathrm{aVLF}$ & $\begin{array}{l}\text { amount of power contained within a } \\
\text { frequency band } 0-0.04 \mathrm{~Hz}\end{array}$ \\
\hline aLF & $\begin{array}{l}\text { amount of power contained within a } \\
\text { frequency band } 0.04-0.015 \mathrm{~Hz}\end{array}$ \\
\hline $\mathrm{aHF}$ & $\begin{array}{l}\text { amount of power contained within a } \\
\text { frequency band } 0.15-0.4 \mathrm{~Hz}\end{array}$ \\
\hline aTotal & total amount of power \\
\hline pVLF & $\begin{array}{l}\text { percentage of power within a frequency } \\
\text { band } 0-0.04 \mathrm{~Hz}\end{array}$ \\
\hline pLF & $\begin{array}{l}\text { percentage of power within a frequency } \\
\text { band } 0.04-0.15 \mathrm{~Hz}\end{array}$ \\
\hline $\mathrm{pHF}$ & $\begin{array}{l}\text { percentage of power within a frequency } \\
\text { band } 0.15-0.4 \mathrm{~Hz}\end{array}$ \\
\hline $\mathrm{nLF}$ & $\begin{array}{l}\text { normalized amount of power within a } \\
\text { frequency band } 0.04-0.015 \mathrm{~Hz}\end{array}$ \\
\hline $\mathrm{nHF}$ & $\begin{array}{l}\text { normalized amount of power within a } \\
\text { frequency band } 0.15-0.4 \mathrm{~Hz}\end{array}$ \\
\hline $\mathrm{LF} / \mathrm{HF}$ & ratio of $\mathrm{LF}$ to $\mathrm{HF}$ \\
\hline peakVLF & peak frequency within the $0-0.04 \mathrm{~Hz}$ \\
\hline peakLF & $\begin{array}{l}\text { peak frequency within the } 0.04-0.15 \\
\mathrm{~Hz}\end{array}$ \\
\hline peakHF & peak frequency within the $0.15-0.4 \mathrm{~Hz}$ \\
\hline SD1 & $\begin{array}{l}\text { standard deviation perpendicular to the } \\
\text { Poincaré diagram line of identity }\end{array}$ \\
\hline SD2 & $\begin{array}{l}\text { standard deviation along to the } \\
\text { Poincaré diagram line of identity }\end{array}$ \\
\hline $\begin{array}{l}\text { SampEn } \\
\text { alpha }\end{array}$ & $\begin{array}{l}\text { sample entropy } \\
\text { scaling exponent of detrended } \\
\text { fluctuation analysis }\end{array}$ \\
\hline alpha1 & $\begin{array}{l}\text { short term scaling of detrended } \\
\text { fluctuation analysis }\end{array}$ \\
\hline alpha2 & $\begin{array}{l}\text { long term scaling of detrended } \\
\text { fluctuation analysis }\end{array}$ \\
\hline
\end{tabular}

\section{Results}

The effect of atrial filling on HRV was quantified by Wilcoxon signed rank sum test for the two pairs of 
experimental conditions: Langendorff mode and working heart mode.

No significant differences ( $\mathrm{p}<0.05$ ) were found among all studied HRV parameters, as calculated from electrograms during perfusion in two different modes.

Comparison of HRV parameters between Langendorff and working heart mode are shown in table 3.

Table 3. Comparison of HRV parameters for Langendorff and working heart mode.

\begin{tabular}{llll}
\hline $\begin{array}{l}\text { HRV } \\
\text { parameter }\end{array}$ & Unit & $\begin{array}{l}\text { Langendorff } \\
\text { mean } \pm \text { std }\end{array}$ & $\begin{array}{l}\text { Working heart } \\
\text { mean } \pm \text { std }\end{array}$ \\
\hline RR mean & $\mathrm{ms}$ & $363.3 \pm 66.08$ & $374.88 \pm 69.7$ \\
RR median & $\mathrm{ms}$ & $362.21 \pm 65.93$ & $373.95 \pm 71.4$ \\
SDNN & $\mathrm{ms}$ & $6.93 \pm 3.79$ & $11.61 \pm 12.6$ \\
NN10 & count & $1.1 \pm 2.23$ & $1.8 \pm 2.49$ \\
pNN10 & $\%$ & $0.14 \pm 0.29$ & $0.21 \pm 0.25$ \\
RMSSD & $\mathrm{ms}$ & $4.55 \pm 5.53$ & $5.73 \pm 6.86$ \\
HRVTi & $\mathrm{ms}$ & $8.6 \pm 5.27$ & $7.69 \pm 5.67$ \\
TINN & $\mathrm{ms}$ & $17.83 \pm 13.76$ & $18.04 \pm 16.29$ \\
aVLF & $\mathrm{ms} 2$ & $13.35 \pm 24.47$ & $89.69 \pm 198.65$ \\
aLF & $\mathrm{ms} 2$ & $4.35 \pm 10.2$ & $30.45 \pm 82.64$ \\
aHF & $\mathrm{ms} 2$ & $3.98 \pm 8.19$ & $14.82 \pm 29.77$ \\
aTotal & $\mathrm{ms} 2$ & $21.67 \pm 38.81$ & $134.96 \pm 231$ \\
pVLF & $\%$ & $72.31 \pm 27.1$ & $67.27 \pm 27.64$ \\
pLF & $\%$ & $14.24 \pm 10.31$ & $14.95 \pm 16.14$ \\
pHF & $\%$ & $13.46 \pm 20.1$ & $17.79 \pm 20.79$ \\
nLF & $\%$ & $0.69 \pm 0.23$ & $0.62 \pm 0.31$ \\
nHF & $\%$ & $0.31 \pm 0.23$ & $0.38 \pm 0.31$ \\
LFHF & & $7.55 \pm 11.65$ & $6.02 \pm 7.86$ \\
peakVLF & $\mathrm{Hz}$ & $0.01 \pm 0.01$ & $0 \pm 0$ \\
peakLF & $\mathrm{Hz}$ & $0.07 \pm 0.02$ & $0.06 \pm 0.02$ \\
peakHF & $\mathrm{Hz}$ & $0.22 \pm 0.08$ & $0.22 \pm 0.07$ \\
SD1 & $\mathrm{ms}$ & $3.22 \pm 3.9$ & $4.04 \pm 4.86$ \\
SD2 & $\mathrm{ms}$ & $8.66 \pm 5.04$ & $15.7 \pm 17.34$ \\
SampEn & - & $0.54 \pm 0.45$ & $0.53 \pm 0.29$ \\
alpha & - & $1.11 \pm 0.48$ & $1.06 \pm 0.44$ \\
alpha1 & - & $0.84 \pm 0.53$ & $0.72 \pm 0.28$ \\
alpha2 & - & $1.19 \pm 0.52$ & $1.19 \pm 0.47$ \\
\hline & & &
\end{tabular}

\section{Discussion}

HRV is the result of the joint effects of several physiological factors, both extracardiac and intracardiac. Extracardiac factors affecting $\mathrm{HRV}$ seem to be well published and widely accepted, but intracardiac factors are subject of state-of-the-art research. Current existing literature supports the presence of intracardiac mechanisms of HRV [7]. Effect of intracardiac mechanisms is especially evident from studies of transplanted hearts and ex-vivo experimental studies [8, 9].

This study confirms the presence of heart rate fluctuation in isolated hearts in both Langendorff and working heart modes.

We further focused on mechanical stimulation of isolated heart associated with heart filling in the working heart mode.

The effect of mechanical stretch stimulus has been previously studied in isolated heart model. It has been proven that increasing right atrial stretch by increasing perfusion pressure increases $\operatorname{HRV}[1,2]$. Mathematical simulation exhibits small increase of HRV variation induced by simulated atrial load [10]. The mechanical stretch of heart during inspirium may affect HRV, since cardiac transplant patients have resting RSA values similar to healthy subjects, although there is no nervous system controlling their heart [9].

Two possible mechanisms explaining how mechanical stimuli can influence HRV have been published.

The mechanical stimulus may affect the open probability of mechanically gated ion channels in sinoatrial node. Mechanical stimulus therefore may produce pacemaker shifts and alter HRV. This effect may be further enhanced due to sinoatrial node functional and anatomic inhomogeneity, since its cells differ in terms of responsiveness to ions [11].

The mechanical stimulus may affect electrotonic interactions between gap junctions. Electrotonic interactions have been found to play a significant role in beating rate irregularity [12]. HRV variability may therefore be affected by changes in gap junction channels characteristic [13].

Those effects may by combined with each other or they may amplify non-mechanical cell characteristics. In order to minimalize undesirable side effects (such as effect of temperature or $\mathrm{pH}$ changes) the temperature was stabilized and closed-loop controlled and hearts were continually oxygenated in this experiment.

The result of this study is that HRV does not differ in the heart perfused on Langendorff mode and working heart mode.

It can be concluded that either heart mechanoreceptors' contribution to HRV is insignificant, or the heart compensatory mechanisms work in the same manner both in Langendorff as well as in working heart modes.

\section{Acknowledgements}

The work was supported by grant projects of the Grant Agency GACR 102/12/2034 and MUNI/A/1365/2015.

\section{References}

[1] Blinks JR. Positive chronotropive effect of increasing right atrial pressure in the isolated mammalian heart. Am J Physiol 1956;186:299-303.

[2] Vick RL. Effects of increased transmural pressures upon atrial and ventricular rhythms in the dog heart-lung preparation. Circ Res 1963;13:39-47. 
[3] Nováková M, Moudr J, Bravený P. A modified perfusion system for pharmacological studies in isolated hearts. Analysis of Biomedical Signals and Images. 15th Biennial International Eurasip Conference Biosignal 2000;162-164.

[4] Kolářová J, Fialová K, Janoušek O, Nováková M, Provazník I. Experimental methods for simultaneous measurement of action potentials and electrograms in isolated heart. Physiol Res 2010;59(S1):71-80.

[5] Task Force of The European Society of Cardiology and The North American Society of Pacing and Electrophysiology. Heart Rate Variability, Standards of measurement, physiological interpretation and clinical use. Europ Heart Journal 1996;354-381.

[6] Ramshur JT. Design, evaluation, and application of heart rate variability analysis software (HRVAS), USA: The University of Memphis, 2010.

[7] Papaioannou VE, Verkerk AO, Amin AS, de Bakker JMT. Intracardiac Origin of Heart Rate Variability, Pacemaker Funny Current and their Possible Association with Critical Illness, 2013: Curr Cardiol Rev.2013;9(1):82-96.

[8] Bernardi L, Salvussi F, Suardi R, et al. Evidence for an intrinsic mechanism regulating heart rate variability in the transplanted and the intact heart during submaximal dynamic exercises. Cardiovasc Res 1990;24(12):969-981.

[9] Hrushesky WHM, Fader D, Schmitt O, et al. The respiratory sinus arrhythmia: a measure of cardiac age. Science 1984;224:1001-1004.

[10] Wilders R, Jongsma HJ, van Ginneken ACG. Pacemaker activity of the rabbit sinoatrial node: a comparison of mathematical models. Biophys J 1991;60:1202-1216.

[11] Clay JR, DeHaan RL. Fluctuations in interbeat interval in rhythmic heart-cell clusters. Biophys J 1979;28:377-390.

[12] Joyner RW, van Capelle FJL. Propagation through electrically coupled cells: how a small SA node drives a large atrium. Biophys J 1986;50:1157-1164.

[13] Jongsma HJ, Tsjernina L, DeBruijne J. The establishment of regular beating in populations of pacemaker heart cells. A study with tissue-cultured rat heart cells. J Mol Cell Cardiol 1983;15:123-133.

Address for correspondence.

Oto Janoušek

Department of Biomedical Engineering

The Faculty of Electrical Engineering and Communication

Brno University of Technology

Technická 3082/12

61600 Brno

Czech Republic

janouseko@feec.vutbr.cz 